\title{
SODIUM AND WATER DEPLETION AND AMMONIA FORMATION BY THE KIDNEYS *
}

\author{
By ROBERTO F. SANTOS
}

(From the Department of Medicine, University of Bahia Medical School, Bahia, Brasil)

(Submitted for publication July 14, 1958; accepted September 25, 1958)

Gamble and associates' work on the mechanism of action of acidifying salts $(1,2)$ originated the impression that the increase in renal excretion of ammonia in response to acidosis of several days' duration might be related to the loss of sodium and water induced by the first doses of the drug (3). This impression has never been adequately substantiated or disproven over the last three decades. In 1952 Peters (4) thus summarized his views on this matter: "The precise stimulus for the secretion of ammonia has not yet been identified. . . . The impression is given that it is substituted for sodium only after a certain amount of this base has been sacrificed and continues to be secreted until the normal supply of sodium in the body has been restored."

Pitts (5) admitted the same possibility while postulating that an increased secretion of adrenal cortical hormones, stimulated by sodium depletion, was the mechanism whereby ammonia excretion increased when ammonium chloride was given to rats.

The degree of acidosis does not seem to be the main regulating influence (6) because in Gamble's experiments ammonia excretion continues to increase even after the acidosis has reached its maximum, and maximal values of ammonia excretion occur while extracellular acidosis is being reversed. Many years ago Briggs $(7,8)$ expressed the opinion that renal excretion of ammonia had nothing to do with regulation of acidbase balance of the "milieu interieur," and that it served the only purpose of avoiding the harmful action of an excessively acid urine on the walls of the urinary tract. His views were based on experiments in which sodium sulfate solution was

* This paper is based on a thesis accepted as part of the requirement for the Professorship of Medicine at the University of Bahia, Bahia, Brasil. The work was aided by a grant from the Conselho Nacional de Pesquisas ( National Research Council), Brasil. infused into dogs with subsequent increase in the excretion of ammonia in a urine of low $\mathrm{pH}$, although there was no sodium or water depletion. Comparable findings had been reported by Hendrix and Sanders (9), and were recently demonstrated by Schwartz, Jenson and Relman (10).

However, all those experiments in which an increase in ammonia excretion could be demonstrated in the absence of sodium and water depletion were of short duration (minutes to hours). It is very likely that this immediate increase in ammonia excretion results from the passage of preformed ammonia from within the tubular cells into the tubular lumen (11). The slow and stepwise increase in ammonia excretion over the period of several days, such as was seen in Gamble's experiments and subsequently confirmed by many others, seems to result from an intensified activity of ammonia-forming enzymes of the tubular cells (12), and might well be controlled by factors different from those which determine the release of preformed ammonia.

The following experiments were planned to investigate whether the depletion of sodium and water which follows the ingestion of acidifying salts is an indispensable factor in determining the coincident increase in urinary ammonia excretion.

Our results demonstrate that even in the absence of depletion of the subjects' own reserves of sodium and water, acidosis induced by ammonium chloride ingestion is accompanied by a stepwise increase in urinary ammonia, comparable to that seen in the experiments of Gamble, Blackfan and Hamilton (2) and of Sartorius, Roemmelt and Pitts (13). Although the increase in ammonia excretion does contribute to the economy of fixed cation, it is not the state of water and sodium depletion which constitutes the stimulating agent for the increase in activity of ammonia-forming enzymes of the renal tubular cells. 
TABLE I

Effect of ammonium chloride on electrolyte metabolism

\begin{tabular}{|c|c|c|c|c|c|c|c|c|c|c|c|c|}
\hline \multirow[b]{2}{*}{ Day } & \multirow[b]{2}{*}{$\begin{array}{l}\text { Body } \\
\text { weight* }\end{array}$} & \multicolumn{7}{|c|}{ Urine } & \multirow{2}{*}{$\frac{\text { Plasma* }}{\substack{\text { Total } \\
\mathrm{CO}_{2}}}$} & \multicolumn{3}{|c|}{ Serum* } \\
\hline & & Vol. & $\mathrm{pH}$ & Ammonia & $\begin{array}{l}\text { Titr. } \\
\text { acid }\end{array}$ & $\mathrm{Cl}^{-}$ & $\mathrm{Na}^{+}$ & $\mathrm{K}^{+}$ & & $\mathrm{Cl}^{-}$ & $\mathrm{Na}^{+}$ & $\mathrm{K}^{+}$ \\
\hline & Kg. & ml./day & & $\begin{array}{c}m E q . / \\
d a y\end{array}$ & $\begin{array}{c}m E q . I \\
\text { day }\end{array}$ & $\begin{array}{c}\text { mEq.I } \\
\text { day }\end{array}$ & $\begin{array}{c}m E q . / \\
\text { day }\end{array}$ & $\begin{array}{c}m E q . / \\
d a y\end{array}$ & $\begin{array}{c}m E q . / \\
L .\end{array}$ & $\begin{array}{c}m E q . / \\
L .\end{array}$ & $\begin{array}{c}m E q . / \\
L .\end{array}$ & $\underset{L}{m E q .}$ \\
\hline 1 & 56.00 & 1,620 & 7.10 & 24.29 & 8.75 & 328.2 & 392.8 & 64.8 & 25.4 & 102 & 140 & 4.1 \\
\hline $\begin{array}{l}2 \\
3\end{array}$ & 57.80 & 2,920 & 7.03 & 39.71 & 16.64 & 663.1 & 695.0 & 77.7 & & & & \\
\hline $\begin{array}{l}3 \\
4 t\end{array}$ & $\begin{array}{r}57.65 \\
5725\end{array}$ & $\begin{array}{l}3,660 \\
3,280\end{array}$ & 6.84 & 41.90 & 16.84 & 675.6 & 702.7 & 71.7 & & & & \\
\hline $\begin{array}{l}41 \\
5\end{array}$ & 57.25 & & $\begin{array}{l}0.52 \\
5.10\end{array}$ & $\begin{array}{r}48.50 \\
102.32\end{array}$ & $\begin{array}{l}27.22 \\
5658\end{array}$ & 0470 & 705.2 & 75.4 & 26.1 & 104 & 142 & 4.5 \\
\hline 6 & 56.65 & 3480 & 5.01 & 120.56 & 6020 & 7419 & 6316 & 940 & 22.0 & 111 & $\begin{array}{l}142 \\
148\end{array}$ & $\begin{array}{l}4.5 \\
42\end{array}$ \\
\hline 7 & 56.35 & 3,210 & 5.12 & 133.08 & 57.14 & 808.3 & 680.5 & 86.7 & 18.6 & 117 & & $\begin{array}{l}4.2 \\
4.2\end{array}$ \\
\hline 8 & 56.45 & & & & & & & & 22.5 & & 143 & 4.2 \\
\hline
\end{tabular}

* Values in these columns were obtained at the beginning of each experimental day.

$\dagger 10 \mathrm{Gm}$. of ammonium chloride was administered orally on each day starting on the fourth day.

\section{MATERIAL AND METHODS}

Five healthy adults, aged 22 to 29 years, were maintained on a constant and adequate diet for a period of seven days, during which they ingested $2.5 \mathrm{~L}$. of a solution containing $9 \mathrm{Gm}$. per $\mathrm{L}$. of sodium chloride and 2.3 Gm. per L. of sodium bicarbonate. In addition, the subjects drank a constant amount of distilled water, which was always more than $1 \mathrm{~L}$. per day.

The first three days of each experiment were taken as controls. From the fourth through the seventh day of each experiment, while still on the same diet and drinking the same amount of the above described solution, the subjects were given orally $10 \mathrm{Gm}$. of ammonium chloride daily, in four equally divided doses.

The urine was carefully collected under toluene for 24 hour periods, and on each specimen the following determinations were done: 1) volume per 24 hours, expressed in milliliters; 2) $\mathrm{pH}$, measured with a "Cambridge" $\mathrm{pH}$ meter, Research Model; 3) titratable acidity, by Henderson and Palmer's method, as described by Consolazio, Johnson and Marek (14); 4) ammonia, by
Conway's method (15) ; 5) chlorides, by Van Slyke and Hiller's method, as described by Hawk, Bernard and Summerson $(16)$; 6) sodium, measured with a "Baird" flame photometer, using an internal standard of lithium sulfate; and 7) potassium, same as for sodium. Values referring to concentration of ammonium, titratable acidity, chloride, sodium and potassium are expressed in mEq. per day.

Blood samples were taken at the beginning of Days $1,4,5,6$ and 7 , and by the end of the seventh metabolic day. All specimens were taken from the veins of the metacarpal region after immersing the forearm in water at $46^{\circ} \mathrm{C}$. for 20 minutes. One aliquot of blood was handled under anaerobic conditions and mixed with heparin. On the plasma separated from that blood, total carbon dioxide content was measured in a manometric Van Slyke apparatus. The rest of the blood was allowed to clot in contact with air in another test tube. On the serum separated therefrom, chloride, sodium and potassium concentrations were measured. The methods were the same as for the respective urine determinations.

TABLE II

Effect of ammonium chloride on electrolyte metabolism

\begin{tabular}{|c|c|c|c|c|c|c|c|c|c|c|c|c|}
\hline \multirow[b]{2}{*}{ Day } & \multirow[b]{2}{*}{$\begin{array}{l}\text { Body } \\
\text { weight* }\end{array}$} & \multicolumn{7}{|c|}{ Urine } & \multirow{2}{*}{$\frac{\text { Plasma* }}{\begin{array}{c}\text { Total } \\
\mathrm{CO}_{2}\end{array}}$} & \multicolumn{3}{|c|}{ Serum* } \\
\hline & & Vol. & $\mathrm{pH}$ & Ammonia & $\begin{array}{l}\text { Titr. } \\
\text { acid }\end{array}$ & $\mathrm{Cl}^{-}$ & $\mathrm{Na}^{+}$ & $\mathrm{K}^{+}$ & & $\mathrm{Cl}^{-}$ & $\mathrm{Na}^{+}$ & $\mathrm{K}^{+}$ \\
\hline $\begin{array}{l}1 \\
2 \\
3 \\
4 \dagger \\
5 \\
6 \\
7 \\
8\end{array}$ & $\begin{array}{c}K g . \\
72.25 \\
73.85 \\
74.00 \\
73.50 \\
72.30 \\
72.30 \\
71.95 \\
71.90\end{array}$ & $\begin{array}{c}m l . / \text { day } \\
1,480 \\
2,367 \\
3,460 \\
4,100 \\
2,550 \\
3,150 \\
3,360\end{array}$ & $\begin{array}{l}6.84 \\
7.10 \\
6.93 \\
6.04 \\
5.25 \\
4.98 \\
5.05\end{array}$ & $\begin{array}{c}m E q . / \\
\text { day } \\
40.75 \\
39.69 \\
46.03 \\
56.09 \\
62.78 \\
105.80 \\
126.64\end{array}$ & $\begin{array}{c}m E q . / \\
\text { day } \\
10.51 \\
9.23 \\
18.68 \\
30.34 \\
43.09 \\
48.51 \\
49.06\end{array}$ & $\begin{array}{c}m E q . l \\
\text { day } \\
479.8 \\
562.9 \\
716.2 \\
936.0 \\
780.3 \\
827.5 \\
794.3\end{array}$ & $\begin{array}{c}m E q . / \\
\text { day } \\
509.1 \\
601.2 \\
751.5 \\
910.2 \\
772.6 \\
745.0 \\
756.0\end{array}$ & $\begin{array}{c}m E q . / \\
\text { day } \\
88.8 \\
60.6 \\
65.0 \\
70.5 \\
72.7 \\
85.0 \\
90.7\end{array}$ & $\begin{array}{l}28.5 \\
19.8 \\
18.4 \\
19.2\end{array}$ & $\begin{array}{l}115 \\
112 \\
112 \\
113\end{array}$ & $\begin{array}{l}150 \\
147 \\
146 \\
146 \\
145\end{array}$ & $\begin{array}{l}4.5 \\
4.9 \\
4.6 \\
4.5 \\
4.4\end{array}$ \\
\hline
\end{tabular}

* Values in these columns were obtained at the beginning of each experimental day.

$\dagger 10 \mathrm{Gm}$. of ammonium chloride was administered orally on each day starting on the fourth day. 
Fig. 1. Effect of Ammonium ChloRIDE on Electrolyte Balance

During the first three days of the study, body water and sodium content were expanded by repeated ingestion of a solution containing sodium chloride and sodium bicarbonate. The ingestion of ammonium chloride starting on the fourth experimental day resulted in loss of body weight which, however, did not fall beyond control levels. In spite of the absence of depletion of the body's own stores of sodium and water, the progressive stepwise increase in urinary ammonia was observed.

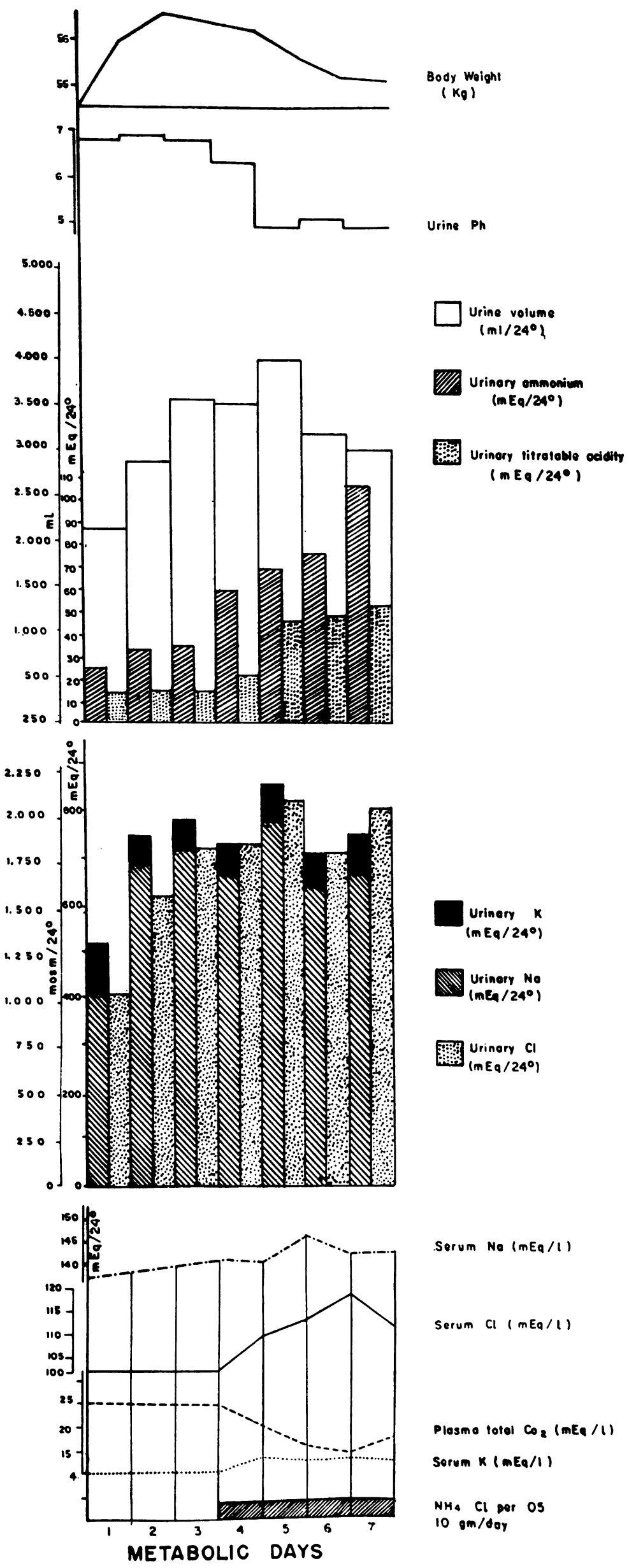




\section{RESULTS}

The results of typical experiments are summarized in Figure 1 and in Tables I and II. None of the subjects complained of any untoward reactions to the experimental regimen. Throughout the experiments, they were capable of carrying on their routine activities in medical wards and laboratories.

Figure 1, for one of the typical experiments, shows how the body weight increased during the control days as a result of the ingestion of sodium chloride and bicarbonate solution. Ingestion of ammonium chloride starting on the fourth experimental day, with ensuing acidosis, caused a decrease in body weight which, however, did not reach precontrol levels. The subject did not sacrifice his own reserves of sodium and water. Ammonia excretion, which had been approximately constant during the control period, increased progressively in a stepwise fashion to levels comparable to those reported by others $(2,13)$ under conditions of progressive sodium and water depletion.

Results comparable to those described above were also found in two other experiments, one of which is shown in Table I. Two other subjects were also submitted to the same experimental regimen, but their body weights fell to less than precontrol levels (see Table II) during administration of ammonium chloride. They, however, showed an increase in urinary ammonia excretion comparable to that found in the three subjects who had obviously not been depleted of their own reserves of sodium and water.

Control levels of urinary $\mathrm{pH}$ were high, and those of titratable acidity were low in all experiments consequent to the ingestion of sodium bicarbonate. As would be expected, urinary $\mathrm{pH}$ decreased and the urinary excretion of chloride and titratable acid increased in all experiments while ammonium chloride was being administered.

The ingestion of ammonium chloride resulted in a marked increase in sodium and in total solutes excretion over and above control levels which were already high. However, we did not find a progressive decrease in the urinary excretion of sodium over several days, such as Gamble and coworkers (2) and Sartorius and associates (13) described in subjects who were being depleted of sodium and water. Nor was the increase in potassium excretion following ammonium chloride administration of such magnitude as that found in Sartorius' experiments.

The total carbon dioxide content of the arterial plasma increased during the control days, due to the ingestion of sodium bicarbonate, and decreased when ammonium chloride was administered. By the fourth day of acidosis, the carbon dioxide content of the plasma was increasing while ammonium chloride was still being given. Serum chloride values were high in all experiments during the control periods and increased further when ammonium chloride was administered. Serum sodium concentration increased during the control days and showed a slight and irregular decrease while the subjects were on ammonium chloride. No regular pattern could be made out of the variations in serum potassium concentration.

\section{DISCUSSION}

Gamble and associates demonstrated that the excretion of fixed cation is maximal on the first day of administration of an acidifying salt and decreases progressively on the following days, while ammonia excretion increases (2). The initial loss of fixed cation is associated with high urinary volume and loss of weight. After discontinuing the acidifying salt, a positive sodium balance occurs, and in spite of elevation of urinary $\mathrm{pH}$, urinary ammonia excretion continues at high levels. This was thought to last until the body regained its stores of fixed cations and water.

Our results demonstrate the same characteristic stepwise increase in ammonia excretion consequent to the ingestion of an acidifying salt over several days, even when the depletion of sodium and water was avoided.

Various types of experiments, some of which were published long ago, have shown that urinary ammonia excretion can increase in the absence of sodium and water depletion. This happens, for instance, when normal human subjects breathe gas mixtures containing carbon dioxide in a concentration of 5 to 6 per cent (17), as well as after infusion of sodium salts of nonreabsorbable anions (8-10). In all those experiments urinary $\mathrm{pH}$ was suddenly brought to very low levels.

Several lines of evidence suggest that renal 
excretion of ammonia can be modified according to two entirely different patterns. Sudden changes in urinary $\mathrm{pH}$ are promptly accompanied by the release of larger or smaller amounts of ammonia, which very likely were previously formed and present inside the tubular cells (11). On the other hand, conditions prevailing inside the tubular cells seem to determine a faster or slower rate of formation of ammonia (12). Thus, a drop in urinary ammonia was found to occur simultaneously with an increase in urinary $\mathrm{pH}$ caused by carbonic anhydrase inhibitors (18), while the prolonged use of carbonic anhydrase inhibitors, with ensuing acidosis, was found to cause increase in urinary ammonia excretion (19). This difference in patterns of change in urinary ammonia excretion is further illustrated by data reported by Sartorius (13), who measured the immediate change in ammonia excretion after administration of ammonium chloride to normal humans and found an increase of several fold within the first two hours. This rate was obviously not maintained throughout the several days during which ammonium chloride was given. It is likely that this large initial increase was due to transfer of preformed ammonia from within the tubular cells to the tubular lumen, as a result of sudden acidification of the urine. The progressive, but much slower, increase of several days' duration would result from the intensified action of ammoniaforming enzymes under the stimulus of acidosis.

These two patterns of change in urinary ammonia excretion seem to be influenced by factors of a different order. Increased ammonia excretion in the absence of sodium and water depletion had been found during experiments of a few hours' duration. This did not rule out the possibility that the same factor of sodium and water depletion might be the stimulus for the stepwise progressive increase in ammonia excretion consequent to the administration of acidifying salts for several days.

In our experiments ammonium chloride was given to normal human subjects preloaded with sodium chloride and bicarbonate. Sodium bicarbonate was added in order to avoid the acidifying effect of large amounts of isotonic sodium chloride solution given prior to the administration of ammonium chloride. Administration of ammonium chloride from the fourth to the seventh experimen- tal days resulted in loss of some of the surplus of water and fixed cation, but in three out of the five experiments, body weight did not reach precontrol levels during the experimental period. These subjects excreted the excess chloride ingested as ammonium chloride along with the fixed cation and the water accumulated during the control days, and did not have to sacrifice their own reserves of sodium and water. The progressive decrease in sodium excretion, which in the experiments of Gamble and of Sartorius indicated the need for the body to save fixed cation, was not present in our experiments. In spite of that, the daily increase in ammonia excretion proceeded at a rate comparable to that described by Gamble (2), and subsequently confirmed by many others $(13,20,21)$, under conditions in which water and sodium depletion did take place. No significant difference in the pattern of ammonia excretion could be detected amongst our own subjects, between those whose body weight remained above precontrol levels throughout the experiment and those who lost some of their own reserves of sodium and water.

The factors that control urinary excretion of ammonia have not yet been fully described. It was already pointed out that in Gamble's experiments the increase in ammonia excretion and the extracellular acidosis failed to follow parallel courses. This can also be seen in the data herein reported, and points to the existence of other factors which determine the progressive and stepwise increase in urinary ammonia excretion. The latter part of Gamble's experiments (2) indicates that urinary ammonia excretion can still be high in long-term experiments in spite of elevation of urinary $\mathrm{pH}$. The increase in excretion of potassium following ammonium chloride administration in our experiments was irregular and small, much less than in Sartorius's experiments. This indicates that potassium depletion in itself should not be considered a prerequisite for the increase in ammonia excretion in response to acidifying salts.

As shown by Davies and Yudkin (22), adaptation of ammonia-forming enzymes of the renal tubular cells to a low $\mathrm{pH}$ proceeds at a slow rate. Schwartz, Jenson and Relman $(10,23)$ suggested that the progressive loss of cation during the first days of administration of the acidifying salt 
would aggravate the difference between the excretion of fixed anions and the fixed cations available for excretion. This would stimulate ammonia formation in a stepwise manner.

\section{CONCLUSIONS}

1. Electrolyte and acid-base studies were made on five normal subjects to determine if cation depletion is essential for progressive stepwise increase in urinary ammonia excretion secondary to administration of acidifying salts.

2. Subjects were maintained on constant diet and fluid intake and given sufficient sodium chloride and sodium bicarbonate orally to expand the extracellular fluid by approximately 1.5 to $2 \mathrm{~L}$.

3 . When extracellular fluid volume was increased, $10 \mathrm{Gm}$. of ammonium chloride was administered daily for four days. This resulted in a progressive excretion of ammonia although body weight measurements indicated that the extracellular fluid volume was still excessive.

4. These results demonstrate that depletion of sodium is not a prerequisite for a sustained increase in urinary ammonia excretion.

\section{ACKNOWLEDGMENT}

The author is grateful to Dr. Alexander Leaf for his assistance in preparing the manuscript.

\section{REFERENCES}

1. Gamble, J. L., Ross, G. S., and Tisdall, F. F. Studies of tetany. I. The effect of calcium chloride ingestion on the acid-base metabolism of infants. Amer. J. Dis. Child. 1923, 25, 455.

2. Gamble, J. L., Blackfan, K. D., and Hamilton, B. A study of the diuretic action of acid producing salts. J. clin. Invest. 1925, 1, 359.

3. Peters, J. P., and Van Slyke, D. D. Quantitative Clinical Chemistry. Vol. 1, Interpretations. Baltimore, Williams \& Wilkins Co., 1932.

4. Peters, J. P. Water balance in health and disease in Diseases of Metabolism, 3rd ed., G. G. Duncan, Ed. Philadelphia, W. B. Saunders Co., 1952, p. 315.

5. Pitts, R. F. Acid-base regulation by the kidneys. Amer. J. Med. 1950, 9, 356.

6. Folling, A. On the mechanism of the ammonium chloride acidosis. Acta med. scand. 1929, 71, 221.

7. Briggs, A. P. Excretion of ammonia and neutrality regulation. J. biol. Chem. 1934, 104, 231.

8. Briggs, A. P. The significance of the urinary ammonia. J. Lab. clin. Med. 1942, 28, 174.
9. Hendrix, B. M., and Sanders, J. P. The effect of injections of sodium phosphates and sodium hippurate upon the excretion of acid and ammonia by the kidney. J. biol. Chem. 1923, 58, 503.

10. Schwartz, W. B., Jenson, R. L., and Relman, A. S. Acidification of the urine and increased ammonium excretion without change in acid-base equilibrium: Sodium reabsorption as a stimulus to the acidifying process. J. clin. Invest. 1955, 34, 673.

11. Clarke, E., Evans, B. M., MacIntyre, I., and Milne, M. D. Acidosis in experimental electrolyte depletion. Clin. Sci. 1955, 14, 421.

12. Rector, F. C., Jr., Seldin, D. W., and Copenhaver, J. H. The mechanism of ammonia excretion during ammonium chloride acidosis. J. clin. Invest. 1955, 34, 20.

13. Sartorius, O. W., Roemmelt, J. C., and Pitts, R. F. The renal regulation of acid-base balance in man. IV. The nature of the renal compensations in ammonium chloride acidosis. J. clin. Invest. 1949, 28, 423.

14. Consolazio, C. F., Johnson, R. E., and Marek, E. Metabolic Methods; Clinical Procedure in the Study of Metabolic Functions. St. Louis, C. V. Mosby Co., 1951.

15. Conway, E. J. Micro-diffusion Analysis and Volumetric Error, 3rd ed. rev. London, Lockwood, 1950.

16. Hawk, P. B., Bernard, L. O., and Summerson, W. H. Practical Physiological Chemistry, 13th ed. New York, Blakiston Co., 1954.

17. Davies, H. W., Haldane, J. B. S., and Kennaway, E. L. Experiments on the regulation of the blood's alkalinity. I. J. Physiol. 1920, 54, 32.

18. Ferguson, E. B., Jr. A study of the regulation of the rate of urinary ammonia excretion in the rat. $\mathrm{J}$. Physiol. 1951, 112, 420.

19. Rector, F. C., Jr., Seldin, D. W., Roberts, A. D., Jr., and Copenhaver, J. H. Relation of ammonia excretion to urine pH. Amer. J. Physiol. 1954, 179, 353.

20. Ryberg, C. On the formation of ammonia in the kidney during acidosis. Acta physiol. scand. 1948, 15, 114.

21. Wood, F. J. Ammonium chloride acidosis. Clin. Sci. 1955, 14, 81.

22. Davies, B. M. A., and Yudkin, J. Studies in biochemical adaptation. The origin of urinary ammonia as indicated by the effect of chronic acidosis and alkalosis on some renal enzymes in the rat. Biochem. J. 1952, 52, 407.

23. Schwartz, W. B., Jenson, R. L., and Relman, A. S. The disposition of acid administered to sodiumdepleted subjects: The renal response and the role of whole body buffers. J. clin. Invest. 1954, 33, 587. 